\title{
Walking away from thoracoabdominal aortic aneurysm repair: Advancing intervention to make it more common
}

\author{
John Bozinovski, MD, MSc
}

\footnotetext{
From the Division of Cardiac Surgery, University of British Columbia and the Royal Jubilee Hospital, Victoria, British Columbia, Canada.

Disclosures: Author has nothing to disclose with regard to commercial support.

Received for publication Oct 25, 2016; accepted for publication Oct 27, 2016; available ahead of print Dec 8, 2016.

Address for reprints: John Bozinovski, MD, MSc, Royal Jubilee Hospital, 106-2020 Richmond Ave, Victoria, British Columbia V8R-6R5, Canada (E-mail: john.bozinovski@ubc.ca).

J Thorac Cardiovasc Surg 2017;153:S42-3

$0022-5223 / \$ 36.00$

Copyright $(2) 2016$ by The American Association for Thoracic Surgery

http://dx.doi.org/10.1016/j.jtcvs.2016.10.042
}

In their article in this issue of the Journal, Oderich and colleagues ${ }^{1}$ have described in depth their extensive experience in treating thoracoabdominal aortic disease with endovascular solutions during a 9-year period. Initial treatment with physician-modified endovascular grafts yielded good results in this cohort, with historically significant risk of morbidity and mortality. In concert with a transition to off-the-shelf and custom-made devices, experience and

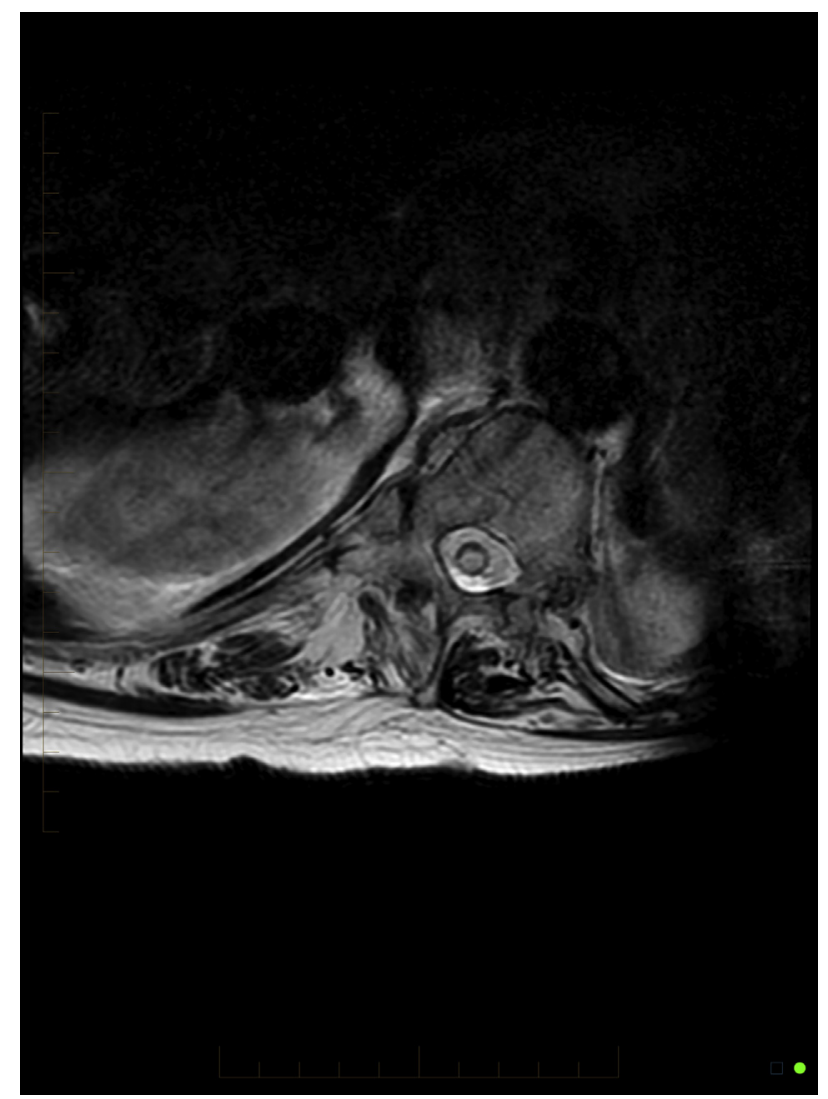

FIGURE 1. Axial magnetic resonance image of spinal cord infarct. Note the white appearance of the infarct in the deeper region of the spinal cord, surrounded by darker appearing normal cord. (Image courtesy of Dr Shane Greek, Department of Radiology, Royal Jubilee Hospital.)

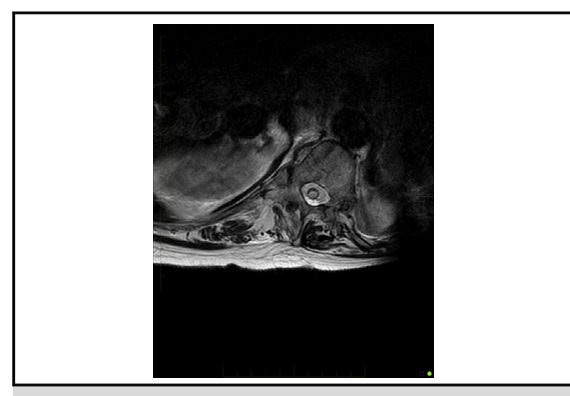

Axial magnetic resonance image of spinal cord infarct.

\section{Central Message}

This commentary is on Oderich and colleagues' comprehensive methodology to mitigate mortality and morbidity in endovascular repair of thoracoabdominal aortic aneurysm and description of their results.

See Article page S32.

procedural related changes produced even better results in the latter half of their endeavors. Surgeons with an interest in thoracoabdominal repair, whether they are proponents of open, endovascular, or hybrid approaches, will find this article full of practical ideas. Regardless of whether it induces one to adopt any of the strategies described, this article will incite surgeons to consider critically their own approaches to this pathology.

Oderich and colleagues ${ }^{1}$ have described a logical, comprehensive methodology to mitigate spinal cord injury (SCI) (Figure 1). That strategy includes staging procedures for extents I and II repairs, extending the use of cerebrospinal fluid drainage to all repairs (including extent IV repairs), using evoked potential (EP) monitoring to guide intraoperative management, and using sequential maneuvers (increasing spinal perfusion pressure, restoring distal blood flow, and temporary aneurysmal sac perfusion) to interrupt threatened SCI. In addition to their low paraplegia rate, Oderich and colleagues $^{1}$ achieved enviable results with respect to renal insufficiency and mortality (survival that compares respectably with that of open repair, ${ }^{2}$ despite an older age and higher risk profile, and with that of hybrid repair ${ }^{3}$ ). They compared their results with those of the largest series of open thoracoabdominal aortic aneurysm repair ${ }^{2}$; however, it would be more appropriate to use the contemporary cohort from that series, in which the rate of paraplegia was $6.5 \%$ and the rate of permanent paraplegia was only $2.6 \%{ }^{4}$ 
With respect to paraplegia, the difficulty lies in knowing what affects it most. Without a comparison group controlling for an intervention of potential benefit, we are left speculating. Looking at this groups' earlier work in 44 thoracoabdominal aortic aneurysm extents I through IV, with an overall $6.8 \%$ SCI rate, we know that 30\% (13 patients) had no change in EPs. ${ }^{5}$ These patients had no SCI. Of the $70 \%(n=31)$ who had changes, $39 \%$ had EPs improved by increasing mean arterial pressure (MAP) and draining more cerebrospinal fluid. These patients also had no SCI. Nineteen patients $(61 \%)$ required further maneuvers (flow was restored to the lower extremity or internal iliac) to restore EPs. Of these 19 patients, 3 $(16 \%)$ had SCI develop despite the intervention. How many would have had SCI develop had flow not been restored to the lower extremity, or had EPs not been monitored and consequently no maneuvers performed, or had EPs not been monitored but the initial maneuvers of using a higher pressure and more cerebrospinal fluid drainage been instituted as routine? A well-designed study assessing the impact of EP monitoring on SCI is needed.
In this study, Oderich and colleagues ${ }^{1}$ did not specify the number of patients who had changes in EPs driving each intervention to mitigate SCI. We look forward to future reports as Oderich and colleagues ${ }^{1}$ follow this cohort out in time, describing other aspects of their analyses in both depth and breadth.

\section{References}

1. Oderich GS, Ribeiro M, Reis de Souza L, Hofer J, Wigham J, Cha S. Endovascular repair of thoracoabdominal aortic aneurysms using fenestrated and branched endografts. J Thorac Cardiovasc Surg. 2017;153:S32-41.

2. Coselli JS, LeMaire SA, Preventza O, de la Cruz KI, Cooley DA, Price MD, et al. Outcomes of 3309 thoracoabdominal aortic aneurysm repairs. J Thorac Cardiovasc Surg. 2016;151:1323-37.

3. Hughes GC, Andersen ND, Hanna JM, McCann RL. Thoracoabdominal aortic aneurysm: hybrid repair outcomes. Ann Cardiothorac Surg. 2012;1: 311-9.

4. Wong DR, Parenti JL, Green SY, Chowdhary V, Liao JM, Zarda S, et al. Open repair of thoracoabdominal aortic aneurysm in the modern surgical era: contemporary outcomes in 509 patients. J Am Coll Surg. 2011;212:569-79; discussion 579-81.

5. Banga PV, Oderich GS, Reis de Souza L, Hofer J, Cazares Gonzalez ML, Pulido JN, et al. Neuromonitoring, cerebrospinal fluid drainage, and selective use of iliofemoral conduits to minimize risk of spinal cord injury during complex endovascular aortic repair. J Endovasc Ther. 2016;23:139-49. 